\title{
3D реконструкція та моделювання після гастректомії з єюногастропластикою при гострокровоточивому раку шлунка
}

\begin{abstract}
Мета роботи: визначити роль 3D реконструкції та моделювання в діагностиці післяопераційних станів після гастректомії із єюногастропластикою з приводу гострокровоточивого раку шлунка.

Матеріали і методи. У дослідження включено 268 пацієнтів після гастректомії, з яких у 165 хворих була гостра шлунково-кишкова кровотеча. 39 пацієнтам виконано тотальну гастректомію в поєднанні з єюногастропластикою при раку шлунка. Розроблено спосіб одномоментної реконструктивної єюногастропластики після тотальної гастректомії шляхом зшивання ручним швом (3) петлі порожньої кишки у вигляді літери букви Ф (“потрійний анастомоз”), а також три способи апаратної (36) єюногастропластики після тотальної гастректомії при раку шлунка за допомогою циркулярних і лінійних степлерів.

Проведено KT-моделювання із 3D реконструкцією у трьох пацієнтів, що перенесли гастректомію із єюногастропластикою (штучний шлуночок) із включенням дванадцятипалої кишки. Визначалась візуалізація та розташування штучного тонкокишкового резервуара шляхом створення його об'ємної моделі з урахуванням просторового розміщення магістральних судин та нервів із подальшим друкуванням моделі на 3D принтері. Для створення індивідуального макету-прототипу (моделі) застосовано технологію FDM (Fused Deposition Modeling) - моделювання методом наплавлення.

Результати досліджень та їх обговорення. Результати досліджень показали, що тотальну гастректомію при раку шлунка у пацієнтів молодого та середнього віку бажано доповнювати одномоментною єюногастропластикою з включенням дванадцятипалої кишки. Після тотальної гастректомії при раку шлунка в разі розвитку патологічних синдромів доцільно використовувати двомоментну реконструктивну єюногастропластику зі створенням штучного тонкокишкового резервуара апаратним способом із включенням ДПК, що покращує якість життя пацієнтів у віддаленому післяопераційному періоді. 3D реконструкція та моделювання після гастректомії із єюногастропластикою з приводу раку шлунка дає змогу оцінити об’єм, синтопію та скелетотопію штучного тонкокишкового резервуара, має суттєве значення в діагностиці післяопераційних станів та патологічних синдромів, прогнозувати перебіг післяопераційного періоду та функціональні результати гастректомії із єюногастропластикою.
\end{abstract}

Ключові слова: рак шлунка; гастректомія; єюногастропластика; 3D реконструкція.

Постановка проблеми і аналіз останніх досліджень та публікацій. Хірургічне лікування ускладненого раку шлунка на сьогодні залишається складною і до кінця не вирішеною проблемою як в онкології, так і в ургентній абдомінальній хірургії [1, 2, 3].

Ускладнення раку шлунка гострою шлунково-кишковою кровотечею зустрічається в 2,7 40,1 \% випадків, і в останні роки, за даними Центрів шлунково-кишкових кровотеч, цей показник має тенденцію до зростання [4]. Більшість хворих надходить у стаціонар із занедбаними формами захворювання (60-80 \%), у яких часто спостерігаються кровотеча (55-60 \%), стеноз (20-25 \%) або перфорація пухлини (13-15 \%) [2, 4-8]. Майже всі дослідники звертають увагу на пряму залежність результатів лікування раку шлунка від його виявлення на ранніх стадіях $[9,10]$. Розробляються методи реконструктивних операцій після гастректомії (ГЕ) із формуванням тонкокишкових резервуарів різних конструкцій з дослідженням функціональних характеристик, переваг та недоліків запропонованих реконструктивних втручань [4, 11-18], що покращують якість життя оперованих пацієнтів [4, 19, 20, 21].

Діагностика післяопераційних станів після ГЕ при раку шлунка $є$ актуальною проблемою невідкладної хірургії та онкології. Дослідження останніх десятиріч вказує на те, що після ГЕ виникають патологічні синдроми (агастральна астенія, демпінг-синдром, єюно-езофагеальний рефлюкс, втрата маси тіла та ін.) у 42 \% пацієнтів, та навіть при відсутності продовження та прогресування пухлинного процесу наявність патологічних синдромів становить серйозну проблему в плані реабілітації хворих у післяопераційному періоді, знижує вірогідність відновлення працездатності та повноцінної соціальної адаптації. Тому пошуки як операційних технологій, у вигляді реконструктивних втручань із формуванням резервуарів, що покращують якість життя пацієнтів [12, 13, 15], так і комп’ютерних із 3D реконструкцією та моделюванням [22], мають значні перспективи в майбутньому. 
Мета роботи: визначити роль 3D реконструкції та моделювання в діагностиці післяопераційних станів після ГЕ із єюногастропластикою (ЄГП) з приводу гострокровоточивого раку шлунка (ГРШ).

Матеріали і методи. У дослідження включено 268 пацієнтів після ГЕ, з яких у 165 була гостра шлунково-кишкова кровотеча. У 39 пацієнтів виконана тотальна ГЕ в поєднанні із ЄГП при ГРШ. Чоловіків було 27 (69,2 \%), жінок - 12 (30,8 \%). Розроблено спосіб одномоментної реконструктивної ЄГП після тотальної гастректомії (Пат. UA № 52020 А) шляхом зшивання ручним швом петлі порожньої кишки у вигляді літери Ф (“потрійний анастомоз”), а також три способи апаратної ЄГП після тотальної гастректомії при ГРШ (Пат. UA № 41335; Пат. UA № 62486; Пат. UA № 62487). Одномоментна реконструктивна ЄГП після тотальної ГЕ виконана ручним (3) або апаратним швом (36) за допомогою циркулярних і лінійних степлерів.

Проведено KT-моделювання із 3D реконструкцією у трьох пацієнтів, що перенесли ГЕ із ЄГП (штучний шлуночок) із включенням ДПК. Визначалася візуалізація та розташування штучного тонкокишкового резервуара шляхом створення його об'ємної моделі з урахуванням просторового розміщення магістральних судин та нервів із подальшим друкуванням моделі на 3D принтері. Основний формат файлів для тримірного 3D друкy - STL [22]. Для створення індивідуального макету-прототипу (моделі) застосовано технологію FDM (Fused Deposition Modeling) - моделювання методом наплавлення. Сучасні FDM 3D-принтери можуть забезпечувати товщину шару матеріалу, з якого будується модель, до 20 мкм. Модель формується шляхом пошарової укладки розплавленої нитки із плавкого робочого матеріалу (пластик) із зменшенням шорсткості поверхні об’єкта за допомогою лазерного полірування [23].

Результати досліджень та їх обговорення. Серед 165 пацієнтів із гострою шлунковою кровотечею, яким була виконана ГЕ, померло 19 (11,5 \%). У 39 пацієнтів після ГЕ з ЄГП розподіл за стадіями пухлинного процесу був таким: ІА ст. - 2 (5,1 \%), ІВ ст. - 4 (10,2 \%), IIA ст. - 4 (10,2 \%), IIB ст. - 7 (17,9 \% ), IIIA ст. - 8 (20,5 \%), IIIB ст. -7 (17,9 \%), IIIC ст. - 5 (12,8 \%), IV ст. - 2 (5,1 \%).

ЄГП сформована за розробленими методиками ручним швом у 3 (7,7 \%) пацієнтів, апаратним - у 36 (92,3 \%). ЄГП виконувалася за методикою Ф-анастомозу (Пат. UA № 52020 А, рис. 1) у 20 па-
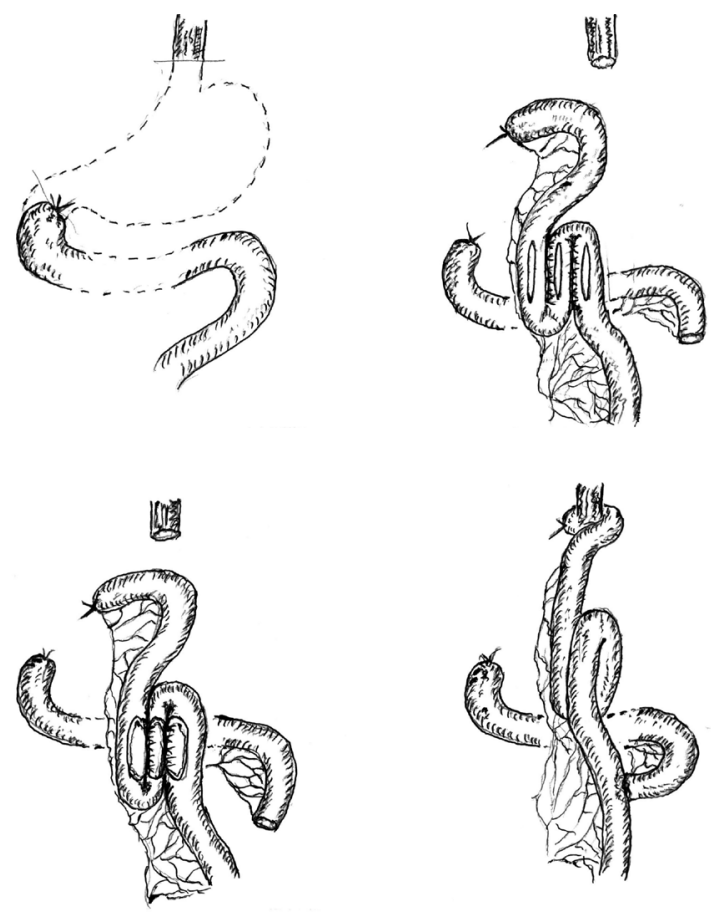

Рис. 1. Формування штучного тонкокишкового резервуару (єюногастропластика) із потрійної петлі порожньої кишки (схема операції).

цієнтів. $\Omega$-loор ЄГП із браунівським анастомозом (Пат. UA № 41335, рис. 2, 3) - у 19 (48,7 \%) хворих на виключеній петлі за Ру (Пат. UA № 62486, рис. 4,5$)$ застосована у $6(15,4 \%)$ пацієнтів, а у 14 (35,9 \%) виконана реконструктивна апаратна
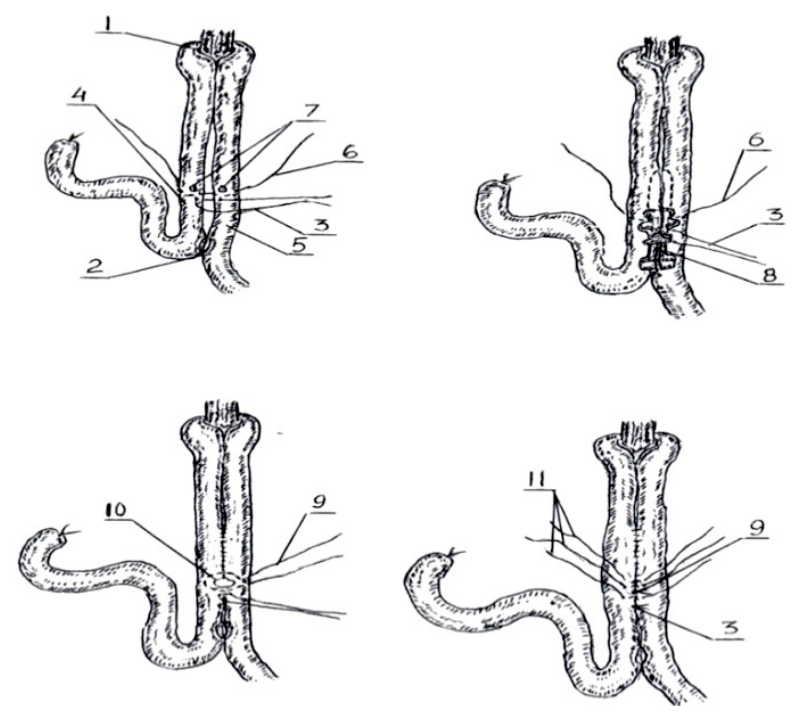

Рис. 2. Апаратна єюногастропластика (Пат. UA № 41335, 2009). Варіант 1 (схема операції). 


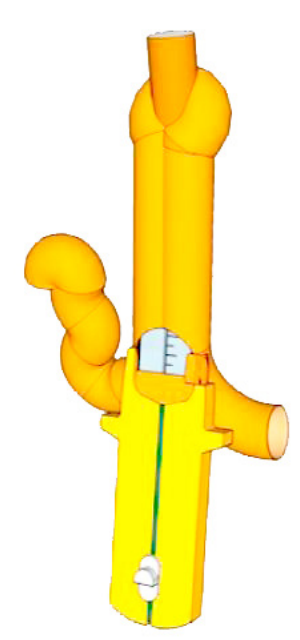

Рис. 3. Віртуальна модель єюногастропластики. Варіант 1.
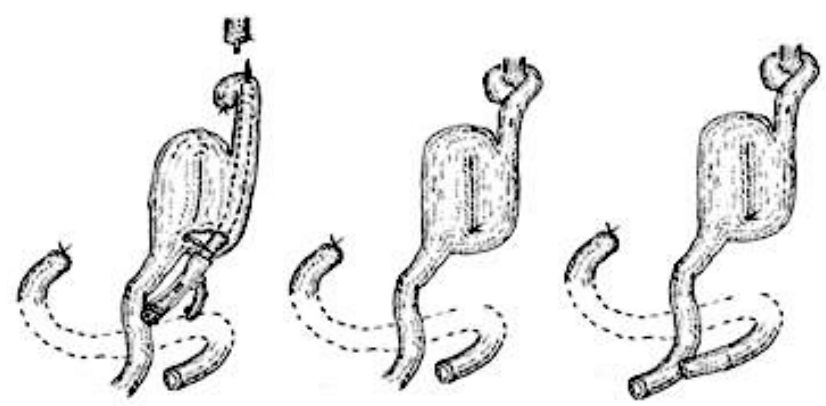

Рис. 4. Апаратна єюногастропластика (Пат. UA № 62486, 2011). Варіант 2 (схема операції).

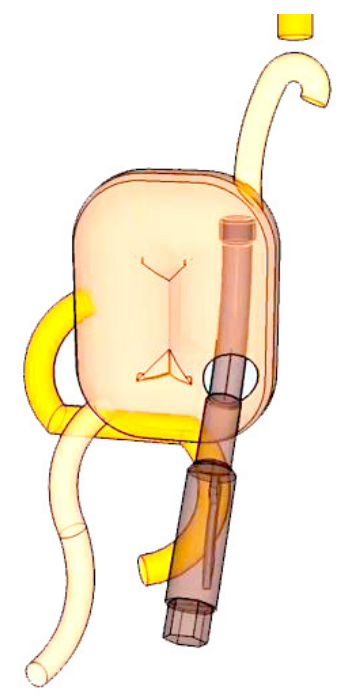

Рис. 5. Віртуальна модель єюногастропластики. Варіант 2.
ЄГП у функціонально вигідному варіанті із включенням ДПК (Пат. UA № 62487, 2011) (рис. 6-8). Лімфодисекція проведена в об’ємі D2(37) і D1(2) із застосуванням ультразвукового скальпеля “Harmonic" та апарата зварки біологічних тканин “Патонмед”. Неускладнений перебіг післяопераційного періоду був у 35 (89,7 \%) хворих, у трьох мав місце гострий післяопераційний панкреатит: у 1 після ЄГП ручним швом та у 2 - після апаратної ЄГП. В одного пацієнта розвинулася перфорація гострої виразки порожньої кишки після ЄГП ручним швом, що потребувала релапаротомії. Летальних випадків не було.
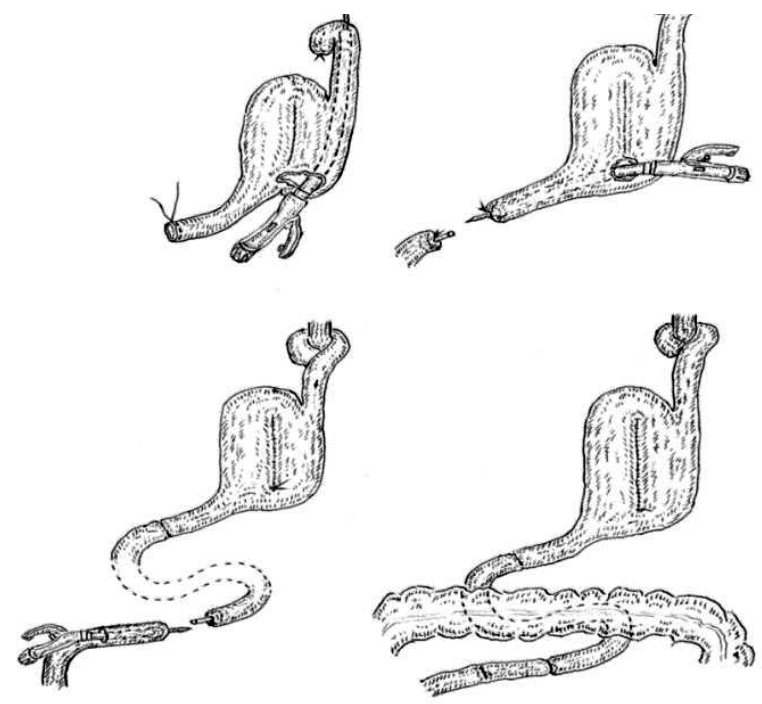

Рис. 6. Апаратна єюногастропластика із включенням ДПК (Пат. UA № 62487, 2011). Варіант 3 (схема операції).

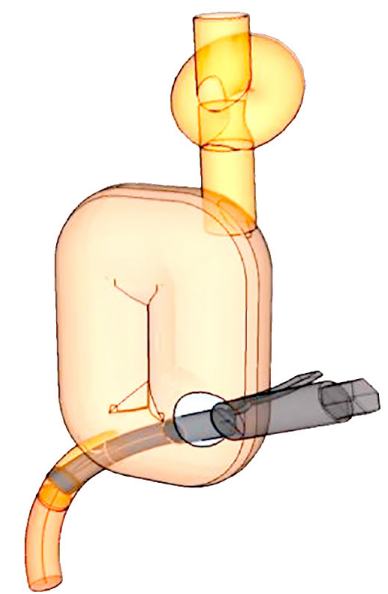

Рис. 7. Віртуальна модель єюногастропластики із включенням ДПК. Варіант 3. 


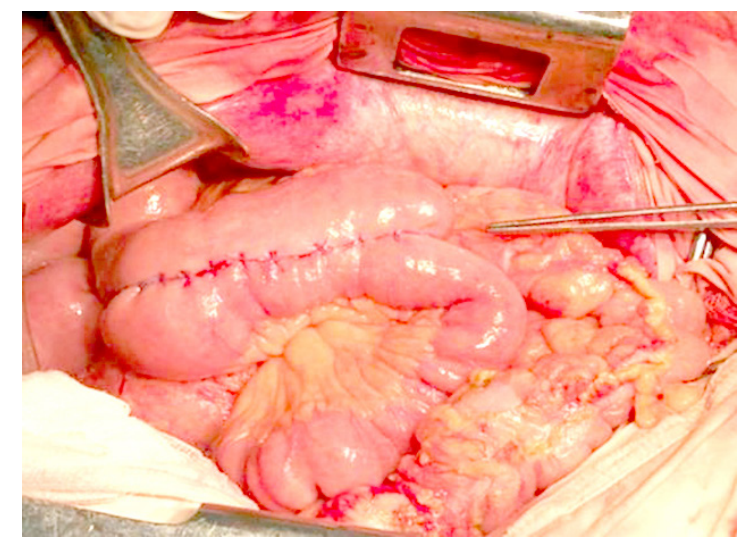

Рис. 8. Сформований тонкокишковий резервуар (ЄГП). Інтраопераційне фото.

У післяопераційному періоді при виконанні рентгенографії (рис. 9) та МСКТ (рис. 10) визначався в лівому піддіафрагмальному просторі штучний тонкокишковий резервуар об'ємом 250500 мл, який з часом має тенденцію до збільшення.

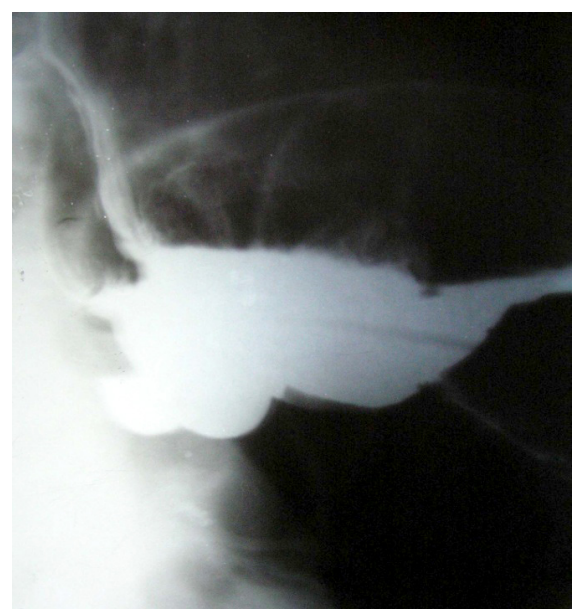

Рис. 9. Рентгенограма єюногастропластики. Хворий 38 р.

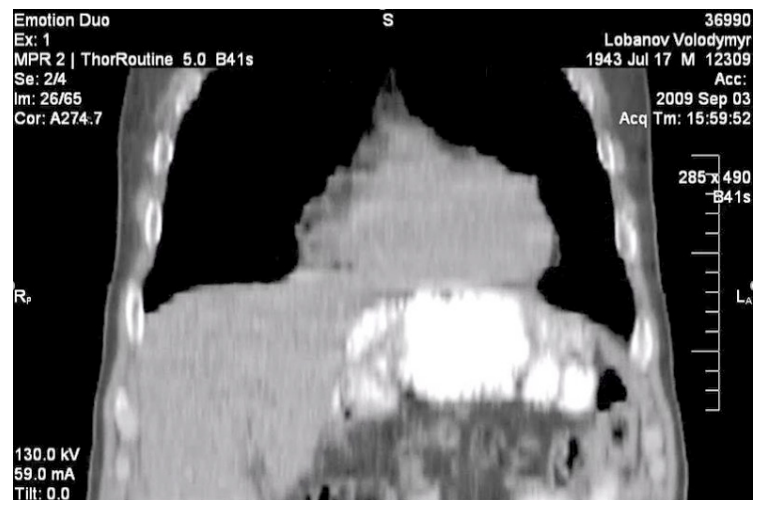

Рис. 10. МСКТ єюногастропластики із контрастуванням.
Сформований штучний тонкокишковий резервуар сприяє більш швидкому збільшенню маси тіла пацієнта, корекції анемії, має антидемпінгові та антирефлюксні властивості, моделює резервуарну функцію втраченого шлунка та, таким чином, покращує якість життя пацієнтів у віддаленому післяопераційному періоді.

Розроблено і впроваджено концепцію двомоментної ЄГП після тотальної ГЕ при ГРШ. На першому етапі встановлюють показання до ЄГП пацієнтам, яким вже була виконана ГЕ $з$ лімфодисекцією, найчастіше в модифікації Савіних або Гіляровича - Юдіна - Шалімова. При розвитку демпінг-синдрому, агастральної астенії, зниженні маси тіла, порушенні дигестивної функції кишкового тракту в післяопераційному періоді та при відсутності даних щодо прогресування пухлинного процесу, на другому етапі, тобто через 4-6 місяців (іноді 1-1,5 року) після тотальної ГЕ, застосовувається реконструктивна ЄГП зі створенням штучного тонкокишкового резервуара. Необхідна ємність резервуара розраховується за системою передопераційного математичного моделювання $з$ урахуванням віку, статі та маси тіла пацієнта. Розроблено шістнадцять варіантів апаратної реконструктивної ЄГП без включення та з включенням ДПК в травний транзит. Функціональні результати реконструктивної ЄГП з включенням ДПК виявилися кращими.

Візуалізація ЄГП (штучного тонкокишкового резервуара) при КТ-моделюванні із 3D реконструкцією дає сприйняття резервуара у просторі, дає змогу визначити його об'єм та розташування відносно прилеглих органів та тканин (рис. 11). Об’єм тонкокишкового резервуара у трьох пацієн-

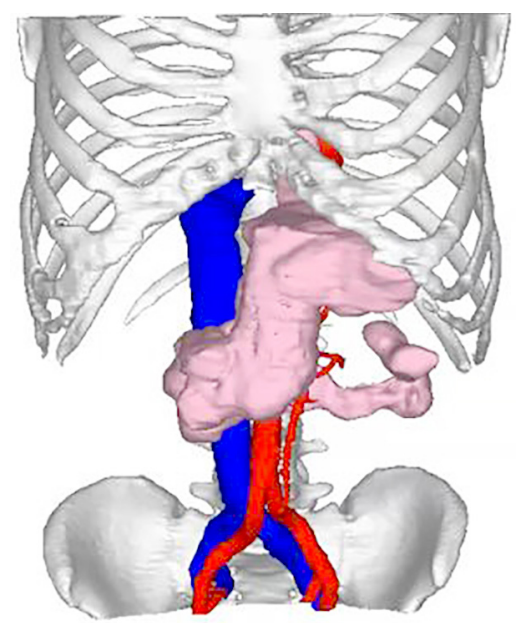

Рис. 11. 3D реконструкція єюногастропластикою. 
тів після ГЕ з ЄГП склав 420 мл, 483 мл та 367 мл. Використання передопераційної 3D реконструкції дає змогу виконати моделювання ЄГП із вказаним об'ємом тонкокишкового резервуара, забезпечує прогнозування оптимального перебігу та реабілітації пацієнтів у найближчому та віддаленому післяопераційному періоді.

Висновки. 1. Тотальну ГЕ при ГРШ у пацієнтів молодого та середнього віку бажано доповнювати одномоментною ЄГП із включенням ДПК.

2. Після тотальної ГЕ при ГРШ в разі розвитку патологічних синдромів доцільно використовува-

\section{СПИСОК ЛІТЕРАТУРИ}

1. Two-layer versus single-layer hand-sewn esophagojejunostomy in totally laparoscopic total gastrectomy for gastric cancer / C. Azócar, C. Marino, S. Revelo [et al.] //13th International Gastric Cancer Congress, May 8-11. - Prague, Czech Republic, 2019. - P. 08-510.

2. Two cases of gastric cancer diagnosed after omental patch repair for gastric perforation [Article in Japanese] / Shinichiro Nakamura, Masami Tabata, Shunta Nakamura [et al.] // Case Reports. - 2020. - Vol. 47 (13). - P. 1842-1844.

3. Ревтович М. Ю. Результаты комплексного лечения рака желудка рT4a-bNO-3МO / М. Ю. Ревтович, О. В. Красько, В. Т. Малькевич. // Евразийский онкологический журнал : междунар. науч.-практ. журнал. - 2021. - Т. 9, № 2. - С. 101-112.

4. Surgical technologies of reconstructive jejunogastroplasty after total gastrectomy / E. Shepetko, P. Fomin, D. Garmash [et al.] //13th International Gastric Cancer Congress, May 8-11. Prague, Czech Repablic, 2019. - P. 07-462.

5. Staged laparoscopic management of locally advanced gastric cancer with outlet obstruction / Lu-Yang Zhang, Jun-Jun Ma, Lu Zang [et al.] // J. Surg. Oncol. - 2021. - Suppl. 1. - P. 8-14. DOI: $10.1002 /$ jso.26342.

6. Bang H. J. Diagnosis and treatment of perforated gastric carcinoma / H. J. Bang, H. Ryu, I. Shin // 13th International Gastric Cancer Congress, May 8-11. - Prague, Czech Repablic, 2019. P. 07-299.

7. Assessment of perforated gastric cancer cases at tane general hospital in Japan / T. Mori, T. Itami, Y. Matsui [et al.] //13th International Gastric Cancer Congress, May 8-11. - Prague, Czech Repablic, 2019. - P. 07-414.

8. Clinicopathological features and disease outcome of complicated gastric cancer with outlet obstruction, perforation or overt bleeding. (Multicenter GIRCG retrospective study) / E. Orsenigo, M. C. Salandini, L. Graziosi [et al.] //13th International Gastric Cancer Congress, May 8-11. - Prague, Czech Repablic, 2019. P. 07-435.

9. The safety of laparoscopic gastrectomy in early gastric cancer patients / J. Nogueiro, V. Devezas, H. Santos-Sousa [et al.] // 13th International Gastric Cancer Congress, May 8-11. - Prague, Czech Repablic, 2019. - P. 07-426.

10. Short term nutritional status and quality of life after laparoscopic total gastrectomy and laparoscopic sub-total gastrectomy for Stage1 gastric cancer / H. Ota, K. Tanabe, Y. Saeki [et al.] // 13th International Gastric Cancer Congress, May 8-11. - Prague, Czech Repablic, 2019. - P. 07-436. ти двомоментну реконструктивну ЄГП зі створенням штучного тонкокишкового резервуара апаратним способом із включенням ДПК, що покращує якість життя пацієнтів у віддаленому післяопераційному періоді.

3. 3D реконструкція та моделювання після ГЕ iз ЄГП із приводу ГРШ дає змогу оцінити об’єм, синтопію та скелетотопію штучного тонкокишкового резервуара, має суттєве значення в діагностиці післяопераційних станів та патологічних синдромів, дозволяє прогнозувати перебіг післяопераційного періоду та функціональні результати ГЕ із ЄГП.

11. Lee I. S. Surgical outcomes and over one year follow-up results of 100 consecutive cases of laparoscopic total gastrectomy using double-stapling overlap method / I. S. Lee // 13th International Gastric Cancer Congress, May 8-11. - Prague, Czech Repablic, 2019. - P. 08-535.

12. Shepetko E. Reconstructive jejunogastroplasty after gastrectomy at bleeding cancer of stomach - long term results and technical peculiarities / E. Shepetko, P. Fomin, A. Shepetko // Journal of the Brazilian Medical Association. Suppl. 7-th International Gastric Cancer Congress. May 9-12, 2007. - P. 168.

13. Babenkov G. D. Combined esophagojejunoduodenoplasty in the prevention and treatment of complications of total gastrectomy / G. D. Babenkov // XXIII Congress surgeons of Ukraine [Electronic resource]: Kyiv, Klin. Khirurgiya, 2015. - P. 36-37. 14. Prospective study of double tract reconstruction (dtr) and roux en y (r-y) after total gastrectomy for gastric cancer / R. Bandurski, B. Kędra, M. Gryko [et al.] // 8th International Gastric Cancer Congress, June 10-13. - Kraków, Poland, 2009. - P. 37.

15. Total laparoscopic reconstruction using J-pouch and linear stapling technique following total gastrectomy / P. Chinnusamy, P. Ramakrichnan, S. R. P. Senthinathan [et al.] // 12th International Gastric Cancer Congress, April 20-23. - Beijing, China, 2017. - P. 92.

16. Evaluation of nerve preservation in the jejunal pouch interposition after total gastrectomy / M. Ikeda, T. Ueda, Y. Ohashi, T. Nanami // 8th International Gastric Cancer Congress, June 1013. - Kraków, Poland, 2009. - P. 42.

17. Kim A. Introduction of modified ab-oral pouch to prevent jejunojejunostomy stricture after total gastrectomy for gastric cancer patients / A. Kim // 13th International Gastric Cancer Congress, May 8-11. - Prague, Czech Repablic, 2019. - P. 07-365.

18. Maksimovic S. M. Our experience with double tract reconstruction after total gastrectomy in patients with gastric cancer / S. M. Maksimovic // Eur. Surg. - 2010. -Vol. 42, Suppl. 235, - P. 36. 19. Long-term quality of life and nutrition status of the aboral pouch reconstruction after total gastrectomy for gastric cancer / C. Tanaka, M. Kanda, T. Yoshikawa [et al.] //13th International Gastric Cancer Congress, May 8-11. - Prague, Czech Repablic, 2019. - P. 07-474.

20. Quality of life after laparoscopic total gastrectomy versus open total gastrectomy: Evaluation with the EORTC30 - QLQ25 questionnaire // 13th International Gastric Cancer Congress, May 8-11. - Prague, Czech Repablic, 2019. - P. 07-421.

21. Laparoscopic Hunt-Lawrence Jejunal pouch for reconstruc- 


\section{ОРИГІНАЛЬНІ ДОСЛІДЖЕННЯ}

tion after total gastrectomy for gastric cancer // J. Laparoendosc. Adv. Surg. Tech. A. - 2021. -Vol. 31 (9). - P. 1051-1054. DOI: 10.1089/lap.2020.0996.

22. Kurenov S. N. Three-dimensional printing to facilitate anatomic study, device development, simulation, and planning in thoracic surgery / S. N. Kurenov // The Journal of Thoracic and Cardiovascular Surgery. - 2015. - Vol. 149, No. 4. - P. 973-979. 23. Using acetone Vapour treatment to improve secondary finishing operations in additive manufacturing / S. Sikder, A. Barari, F. Kaji, H. Kishawy // Proc. ASPE, 3898, 2014. - 2 p.

\section{REFERENCES}

1. Azócar, C., Marino, C., Revelo, S., Lemus, M., Grasset, E., Muñoz R., ... Crovari F. (2019). Two-layer versus single-layer hand-sewn esophagojejunostomy in totally laparoscopic total gastrectomy for gastric cancer. 13th International Gastric Cancer Congress. Prague, Czech Repablic, May 8-11. (pp 08-510).

2. Shinichiro Nakamura, Masami Tabata, Shunta Nakamura, Yuki Segi, Yu Fujimura, Ryosuke Desaki, ... Takayuki Sanda. (2020). Two cases of gastric cancer diagnosed after omental patch repair for gastric perforation. [in Japanese] Case Reports, 47 (13), 1842-1844.

3. Revtovich, M.Yu., Krasko, O.V., \& Malkevich, V.T. (2021). Rezultaty kompleksnogo lecheniya raka zheludka pT4a-bNO$3 \mathrm{MO}$ [Results of complex treatment of gastric cancer pT4a-bNO3MO]. Evraziyskiy onkologicheskiy zhurnal - Eurasian Journal of Oncology, 2, 101-112 [in Russian]

4. Shepetko, E., Fomin, P., Garmash, D., Kozak, Y., Koshman, I., Azarenkov, A., Muzychuk B. (2019). Surgical technologies of reconstructive jejunogastroplasty after total gastrectomy. 13th International Gastric Cancer Congress. Prague, Czech Repablic, May 8-11. (pp 07-462).

5. Lu-Yang Zhang, Jun-Jun Ma, Lu Zang, Hi-Ju Hong, Ai-Guo Lu, Zi-Rui He, ....Min-Hua Zheng (2021). Staged laparoscopic management of locally advanced gastric cancer with outlet obstruction. J Surg Oncol. Suppl. 1, 8-14. Retrieved from: DOI: $10.1002 /$ jso.26342.

6. Bang, H.J., Ryu, H., Shin, I. (2019). Diagnosis and treatment of perforated gastric carcinoma. 13th International Gastric Cancer Congress. Prague, Czech Repablic, May 8-11. (pp 07-299).

7. Mori, T., Itami, T., Matsui, Y., Koike, H., Kudose, Y., Shoji, T., ...Niwa, H. (2019). Assessment of perforated gastric cancer cases at tane general hospital in Japan. 13th International Gastric Cancer Congress. Prague, Czech Repablic, May 8-11. (pp 07-414).

8. Orsenigo, E., Salandini, M.C., Graziosi, L., Ministrini ,S., Giacopuzzi, S., Scorsone, L., ...Carlucci, M. (2019). Clinicopathological features and disease outcome of complicated gastric cancer with outlet obstruction, perforation or overt bleeding. (Multicenter GIRCG retrospective study). 13th International Gastric Cancer Congress. Prague, Czech Repablic, May 8-11. (pp 07-435).

9. Nogueiro, J., Devezas, V., Santos-Sousa, H., Sousa, F., Fernandes, C., Pereira, A., ... Costa-Maia, J. (2019). The safety of laparoscopic gastrectomy in early gastric cancer patients. 13th International Gastric Cancer Congress. Prague, Czech Repablic, May 8-11. (pp 07-426).

10. Ota, H., Tanabe, K., Saeki, Y., Yamamoto, Y., Saito R., Ohdan, H. (2019). Short term nutritional status and quality of life after laparoscopic total gastrectomy and laparoscopic sub-total gastrectomy for Stage1 gastric cancer. 13th International Gastric Cancer Congress. Prague, Czech Repablic, May 8-11. (pp 07-436).

11. Lee, I.S. (2019). Surgical outcomes and over one year follow-up results of 100 consecutive cases of laparoscopic total gastrectomy using double-stapling overlap method. 13th International Gastric Cancer Congress. Prague, Czech Repablic, May 8-11.
12. Shepetko, E., Fomin, P., Shepetko, A. (2007). Reconstructive jejunogastroplasty after gastrectomy at bleeding cancer of stomach - long term results and technical peculiarities. Journal of the Brazilian Medical Association. Suppl. 7-th International Gastric Cancer Congress. May 9-12.

13. Babenkov, G.D. (2015). Combined esophagojejunoduodenoplasty in the prevention and treatment of complications of total gastrectomy. XXIII congress surgeons of Ukraine [Electronic resource]: Collection of Scientific Works. Electron. Dan. (80 min 700 MB). Klin. Khirurgiya - Clinical Surgery, Kyiv.

14. Bandurski, R., Kędra, B., Gryko, M., Kukliński, A., Kamocki, Z., Piotrowski, Z. (2009). Prospective study of double tract reconstruction (dtr) and roux en y (r-y) after total gastrectomy for gastric cancer. 8th International Gastric Cancer Congress. Kraków, Poland, June 10-13.

15. Chinnusamy, P., Ramakrichnan, P., Senthinathan, SRP, Raj, P., Natarajan, R. (2017). Total laparoscopic reconstraction using J-pouch and linear stapling technique following total gastrectomy. 12th International Gastric Cancer Congress, Beijing, China, April 20-23.

16. Ikeda, M., Ueda, T., Ohashi, Y., Nanami, T. (2009). Evaluation of nerve preservation in the jejunal pouch interposition after total gastrectomy. 8th International Gastric Cancer Congress. Kraków, Poland, June 10-13.

17. Kim, A. (2019). Introduction of modified ab-oral pouch to prevent jejunojejunostomy stricture after total gastrectomy for gastric cancer patients. 13th International Gastric Cancer Congress. Prague, Czech Repablic, May 8-11. (pp 07-353).

18. Maksimovic, S.M. (2010) Our experience with double tract reconstruction after total gastrectomy in patients with gastric cancer. Eur. Surg. Suppl. 235, 42, 36.

19. Tanaka, C., Kanda, M., Yoshikawa, T., Cho, H., Ito, Y., Matsui, T., Nakayama, H., ... Kodera, Y. (2019). Long-term quality of life and nutrition status of the aboral pouch reconstruction after total gastrectomy for gastric cancer. 13th International Gastric Cancer Congress. Prague, Czech Repablic, May 8-11. (pp 07-474).

20. Navarrete, A., Humeres, R., Werner, K., Manriquez, L., Sepulveda, R. (2019). Quality of Life After Laparoscopic Total Gastrectomy versus Open Total Gastrectomy: Evaluation with the EORTC30 - QLQ25 questionnaire. 13th International Gastric Cancer Congress. Prague, Czech Repablic, May 8-11. (pp 07-421).

21. Caroline E Poorman, Ankit D Patel, S Scott Davis, Edward Lin (2021). Laparoscopic Hunt-Lawrence Jejunal pouch for reconstruction after total gastrectomy for gastric cancer. J. Laparoendosc. Adv. Surg. Tech. A., 31 (9), 1051-1054. Retrieved from: DOI: 10.1089/lap.2020.0996.

22. Kurenov, S.N. (2015). Three-dimensional printing to facilitate anatomic study, device development, simulation, and planning in thoracic surgery The Journal of Thoracic and Cardiovascular Surgery, 149, (4), 973-979.

23. Sikder, S., Barari, A., Kaji, F., \& Kishawy, H. (2014). Using acetone vapour treatment to improve secondary finishing operations in additive manufacturing. Proc. ASPE, 3898. 
E. M. SHEPETKO ${ }^{1,2}$, V. V. SKIBA ${ }^{1}$, S. V. BURBURSKA ${ }^{3}$, D. O. GARMASH ${ }^{2}$, M. V. BILYACHENKO², V. V. IEFREMOV², M. O. LOGOSHA

Kyiv Medical University ${ }^{1}$

Innovative Surgical Center "Adonis - Lab SP"2

Laboratory of Biomedical Engineering of the Institute of Traumatology and Orthopedics of the National Academy of Medical Sciences of Ukraine ${ }^{3}$, Kyiv

\section{D RECONSTRUCTION AND MODELING AFTER GASTRECTOMY WITH JEJUNOGASTROPLASTY FOR ACUTE BLEEDING GASTRIC CANCER}

The aim of the work: to determine the role of $3 \mathrm{D}$ reconstruction and modeling in the diagnosis of postoperative conditions after total gastrectomy (GE) for acute bleeding gastric cancer (ABGC).

Materials and Methods. The analysis included 268 patients after GE, 165 of them had acute gastrointestinal bleeding. In 39 patients, total GE was performed in combination with JGP for ABGC. The method has been developed for one-stage reconstructive JGP after total GE by hand suturing (3) of a loop of the small intestine in the form of the letter F ("triple anastomosis"), and three methods of hardware (36) JGP after total GE for ABGC using circular and linear staplers.

CT - modeling with 3D reconstruction was performed in three patients who underwent GE with JGP (artificial stomach) with the inclusion of the duodenum. The visualization and location of the artificial small intestinal reservoir was determined by creating its volumetric model, taking into account the spatial location of the great vessels and nerves, followed by printing the model on a 3D printer. To create an individual mock-up prototype (model), the FDM (Fused Deposition Modeling) technology is applied - modeling by the fused deposition method.

Results and Discussion. The research results have shown that it is desirable to supplement the total GE for ABGC in young and middle-aged patients with simultaneous JGP with the inclusion of the duodenum. After a total GE for ABGC with the development of pathological syndromes, it is advisable to use a two-stage reconstructive JGP with the creation of an artificial small bowel reservoir by a hardware method with the inclusion of a duodenum, which improves the quality of life of patients in the long-term postoperative period. 3D reconstruction and modeling after GE with JGP for ABGC allows to estimate the volume, syntopias and skeletotopy of the artificial small bowel reservoir, is essential in the diagnosis of postoperative conditions and pathological syndromes, and allows predicting the course of the postoperative period and the functional results of GE with JGP .

Key words: gastric cancer; gastrectomy; jejunogastroplasty; 3D reconstruction. 